\title{
Sharing Practical Knowledge in Hostile Environments: A Case Study
}

\author{
Gustavo Guzman \\ g.guzman@griffith.edu.au \\ Griffith University Business School \\ Gold Coast Campus, Griffith University \\ PMB 50 Gold Coast MC \\ Queensland 9726 Australia \\ Phone +617 55528919 \\ Fax +617555 29206
}

Acknowledgement. The author thanks Milena Machado (DEP/UFMG) for her research assistance in the development of this paper, and to the anonymous reviewers of the Journal of Workplace Learning for their valuable feedback. 


\title{
Sharing Practical Knowledge in Hostile Environments: A Case Study
}

\begin{abstract}
Purpose - This paper presents an empirical contribution towards the understanding of the process of sharing practical knowledge (PK) in a hostile work environment. The particular focus is an instance of the process of sharing PK between experienced and non-experienced workers in a biopharmaceutical industry.

Methodology - An interpretive perspective was applied in the inductive and qualitative empirical study. Case study methodology was applied in order to analyse the sharing of practical knowledge. Findings - Research findings from this study have unravelled characteristics of this process that to date have not been discussed in the literature. First, Learning-by-observing has limitations in promoting PK sharing in hostile environments. Second, because there is a wide range of alternative solutions for performing a specific task, sharing PK lends itself to political uses. Third, socialisation is important in order to facilitate the sharing of PK, but it is not enough. Political issues surrounding PK sharing shape socialisation processes and therefore provide a better explanatory base for PK sharing. Fourth, the use of standard work processes to share PK is limited in complex tasks. Thus, it is argued that the main features of PK support high levels of uncertainty that in turn favours the use of political behaviour in the process of sharing PK.

Originality - Focussing on sharing PK in hostile environments is important since the literature has mainly focussed on organisations in which consensus and participation were either implicitly or explicitly assumed.
\end{abstract}

Paper Type Case study

Keywords Bio-pharmaceutical industry, Knowledge sharing, Practical knowledge 


\section{INTRODUCTION}

The importance and significance of Practical Knowledge (PK) have already been pointed out by social scientists (Reckwitz, 2002; Bourdieu, 1990; Schatzki, Knorr-Cetina and Von Savigny, 2001) and economists (Dosi, Nelson and Winter, 2002). In the organisation and management fields, the theme of exploitation of practical knowledge (PK) in industrial settings has been taken up by the literature (e.g. Orr, 1996; Nicolini, Gherardi and Yanow, 2003; Styhre, Josephson and Knauseder, 2006; Tsoukas, 2006). In general terms, the PK literature is largely derived from the disciplines of cognitive education (Brown, Collins and Duguid, 1989; Billett, 1994; Lave and Wenger, 1991), health (Carper, 1978; Berragan, 1998) and anthropology (O’Connor, 2005). It has focussed on the examination of knowledge sharing and learning processes in non-routine work settings such as in adult education, nursing or craft work (e.g. glassblowing). As a result, important insights into the epistemology of practical work as well as on the process of sharing practice have been developed. The literature has advanced some of the key features, the role of the different components of the 'learning' process and the contextual conditions to support PK sharing in workplaces.

In this paper, however, rather than focussing on collaborative and consensual environments reigning in most craft and education environments, the focus is on industrial environments in which job activities unfold under significant social and political constraints. Billett (1996) for example, warned that socio-political issues usually interfere with the PK sharing process. This research takes this observation further and examines a stance of PK transfer in hostile workplace environments. Following Burrell and Morgan's (1979) radical perspective, this study takes the view that hostile workplace environments are likely to be more the norm than the exception. Pluralistic goals, hierarchic control, worker's resistance and contest for material or symbolic resources resulting in low trust and conflict, that permeate decision-making and negotiation processes during task performance, are some of the features of hostile industrial environments that the labour process literature (Burawoy, 1979; Storey, 1983) has documented. Contemporary manufacturing practices — such as the application of JIT and TQM — do not seem to break from past experience (Delbridge, 2000). Moreover, hostile workplace environments can vary from non-compliance, to hostility, passing through withdrawal and denial (Ackroyd and Thompson, 1999).

In the present study, hostile work environments are defined as related to both organisational and social contexts. From the organisational perspective, hostile environments results from tight 
division of labour, task fragmentation and the existence of vertical supervisory hierarchies. From the social perspective, hostile environments means low inter-personal trust and unwillingness of experts to mentor novices. This is created by uncertainty and ambiguity regarding social relationships and outcomes of proposed changes. This study therefore, recognising that both cooperation and conflict co-exist in social life (Watson, 1995), moves away from unitarist perspective (Burrell and Morgan, 1979) and emphasises the role of political issues in order to better understand PK sharing processes in hostile environments. Political issues are related to situations and events in which individuals or groups, consciously or unconsciously, attempt to influence, trade, lobby or negotiate others' attitudes, behaviours and decisions in order to direct how material or symbolic resources are produced, used and distributed. (Buchanan and Badham, 1999; Leftwich, 1983). In the case of workplace learning activities for example, Billett (1996) has recognised its political nature since he noted that learning involves negotiation, influencing and compromise.

The goal of this study, therefore, is to analyse and evaluate an instance of the process of sharing PK in a 'hostile' industrial setting from the socio-organisational perspective by examining the social processes that shape PK sharing between experienced and inexperienced practitioners. That is, the empirical evidence focuses on an organisation that has not formally planned and organised the PK sharing process and where there is resistance by experts to share their PK with inexperienced individuals. Focussing on sharing PK in hostile environments is important since the literature has mainly focussed on organisations in which consensus and participation were either implicitly or explicitly assumed (Garrick, 2001; Handley, Sturdy, Fincham and Clark, 2006).

The empirical evidence presented in this research is based on a case study in a biopharmaceutical industry. It focuses on the mastery of 'routine' tasks by inexperienced personnel up to the point where these personnel are able to "work intuitively, drawing almost unconsciously on a repertoire of context specific paradigm cases” (Rolfe, 1997, p. 94) to solve context-specific problems by adapting procedures, equipment and materials. This implies that newcomers need to achieve different goals (e.g. learn the sequence of a set of activities or specific operational conditions of individual equipment) and simultaneously need to perform different activities (such as impression management or developing interpersonal relationships) under social and cognitive constraints (Fuhrer, 1993).

It should be noted that this is not a study of PK sharing between experts and novices at the individual level. It is also not about PK sharing within an established community of practice in which consensual and participative practices prevail. Rather, it considers the adverse socio- 
organisational forces surrounding the expert-inexperienced relationship by focussing on the PK sharing process between experts and novices. Moreover, this study focuses on the interdependent nature of interactions among individuals (Ickes and Gonzales, 1996) and, between individuals and artefacts (Nicolini et al., 2003).

The paper is organised as follows. The next section reviews the literature on the nature and processes of PK, highlighting key concepts, agreements and controversies. Then the adopted methodological strategy and applied research methods are presented and justified. The following section presents and discusses the empirical findings. Finally, in the conclusions it is argued that in hostile work environments, the political dimension seems to be crucial to either support or constrain the process of PK sharing.

\section{The Concept of Practical Knowledge}

The literature has agreed on the notion that PK is related to a specific situation, which is inseparable from action, is personal, temporal and directly connected to prevalent traditions (Polanyi, 1958; Nyiri, 1988; Baumard, 1999; Orlikowski, 2002). PK is situational because it refers to ongoing actions occurring in a specific context, which, in turn, is emergent, temporal and social (Tsoukas, 2000; Thompson and Walsham, 2004). PK is relational since different human and technological artefacts, having different histories and logics of action, mediate it (Nicolini, Gherardi and Yanow, 2003). Because PK is personal, it might involve cognition, feelings, intuition, human motor activity and social identity (Polanyi, 1958; Moch, 1990; Handley et al., 2006). Because practice unfolds in time, PK can also be approached as temporal, irreversible and urgent (Bourdieu, 1990). Finally, PK also possesses semantic aspects related to the meaning given to the act of practice (Weick, 1995; Tsoukas, 2005). Those dimensions of practice are usually combined with routines, procedures and equipment (Dougherty, 2004). That is why PK cannot be 'transferred' but is 'learned’ during situated action (Lave, 1993; Revans, 1966).

The idea of PK significantly overlaps with concepts such as practice and knowing. Practice is the actual realisation of a sequence of actions undertaken by a person. This is what Argyris and Schön (1974) called theories-in-use. They explained that the person executing the action has specific assumptions regarding "self, others, the situation and the connections between action, consequence and situation" (p. 7). Practice, therefore, refers "not only to what one does, but also to how one thinks about what one and others do” (Raelin, 2005, p. 83). 
Knowing is a form of social practice that involves "knowledge in action situated in the historical, social and cultural contexts in which it emerges and [is] embodied in a variety of forms and media” (Nicolini et al., 2003, p. 3). This means that knowing precedes knowledge. In other words, knowing involves "someone drawing distinctions ... Knowing how to act within a domain of action is to make competent use of the distinctions constituting that domain” (Tsoukas, 2000, p. 106).

Practice and knowing, therefore, are connected, since a prerequisite for practice is knowing, which can be either conscious or automatic. Because the literature is spread, Nicolini et al. (2003) have differentiated four traditions within the practice-based approach: knowing as culture and aesthetic understanding; community of practice; activity systems; and sociology of translation. It must be noted that only the last two approaches consider knowing as a socially distributed phenomenon that is mediated by language, technology collaboration and control (cf. Blackler and McDonald, 2000). Notably, the practice-based literature has recognised the action and the mental dimensions of PK. However, while the former emphasises action, the latter focuses on the intellectual processes necessary to perform the action. Smith (1988, pp. 2-3) has expressed a more encompassing conceptualisation that combines actions with meaning, emotions and experience within a specific context.

[PK has] ... been formed by our previous experiences and by our immersion in our present perceptual environment to the extent that the information taken in by our senses is already, in normal circumstances, endowed with meaning ... our sensory contents are a matter of holistic structures, experienced as being tied intrinsically to certain kinds of surrounding conditions and to certain characteristic presuppositions and outcomes. Such outcomes are, most importantly, regularly recurring, so that we have been able to build up through experience a repertoire of perceptual structures which we are able spontaneously to call in aid in relevant circumstances.

A key disagreement in the PK literature is related to the question of whether PK resides in the mind of the person performing the action (epistemology of possession) or if PK is 'part of practice’ (epistemology of practice) (Cook and Brown, 1999). Some writers see practice as something that resides in the mind of persons and can be appropriately transmitted either by mental processes (Gherardi, 2000) or through non-verbal signing associated with novices observing 
expert's practicum (Gourlay, 2004). Other authors have clearly suggested that PK can only be acquired "through experience, that is, through repeated trials, failing, succeeding, wasting time and effort ... getting a feel for a problem, learning when to go by the book and when to break the rules" (Nyiri, 1988, p. 20). This implies that, because PK is tacit, it "cannot be 'captured', 'translated' or 'converted', but only displayed and manifested, in what we do" (Tsoukas, 2005, p. 426). A third group of authors (Handley et al., 2006; Brauner, Becker and Jordan, 2005; Baumard, 1999) have adopted a middle position. They argue that PK has both tacit and explicit dimensions. On the one hand, we can perform a task automatically, unconsciously and effortlessly. On the other hand, PK involves both the physical realisation of actions and the accomplishment of social relations. In this study, following the latter position, the focus is on the social processes surrounding both the action and the intellectual dimensions of PK.

From the above discussion, it is possible to suggest that PK has, on the one hand, a tacit and explicit dimension, and on the other hand, an intellectual and action dimension. Rather than discrete entities, these dimensions represent a continuum in which their constitutive aspects might evolve over time. The tacit dimension involves the unconscious mental knowledge as well as the conscious but unarticulable knowledge that a person has about how to perform a specific task. The explicit dimension refers both to templates on how to do specific practical activities and to the already 'objectivised' practical knowledge. For example, applying the well-known Japanese poka-yoke technique, some practical knowledge can be objectivised in a physical mechanism. The intellectual dimension refers to the previous knowledge and experience that the person has. That is, it involves the conscious-unconscious intuitive knowledge that is applied in the ongoing action in combination with artefacts, materials and other people (Eraut, 2000). The action dimension refers to the actual crystallisation of practice and involves how people perform tasks. This dimension can only exist in situated activity (Brown and Duguid, 2001) and its realisation is experience-based since individuals actively construct their experience through action (Garrick, 2001).

PK, therefore, can be better understood if viewed as a matrix that has, on the one axis, tacit and explicit dimensions and on the other, intellectual and action dimensions. Integrating those dimensions, it is possible to observe four types of PK (see Figure 1).

INSERT FIGURE 1 HERE 
Intellectual knowledge is tacit (quadrant 1) when previous knowledge cannot be expressed with words, when it is unconscious or when the person is unaware of possessing this knowledge. That is, this type of knowledge can be effortlessly and automatically applied in order to perform a specific action. Nicolini et al. (2003) called this 'knowing' and Scribner (1986) called it 'practical thought'. Intellectual knowledge is explicit (quadrant 2) when the person is aware of possessing specific (prior) knowledge, and can consciously express it with words. This is what Blackler (1995) has called encoded knowledge and Ryle (1962) know-how. This type of PK, however, is usually insufficient to guide how to perform actions (Styre, Josephson and Knauseder, 2006). Similarly, action can be both tacit and explicit (Eraut, 2000). Action is tacit (quadrant 3) when it has been routinised, through repetition, into the unconscious performance of a set of tasks. Tasks, therefore, can be performed intuitively and unconsciously and the individual is unable to explain how actions are performed (Eraut, 2000). Action is explicit (quadrant 4) when there is a deliberate will (and competency) to perform a practical task. The individual is, at least partially, able to explain how tasks are performed. It must be noted that all those types cannot exist in isolation. They only make sense when they are integrated.

\section{The Process of Practical Knowledge Sharing}

The process of sharing PK has been the focus of research in a wide range of literatures. The workplace learning literature (cf. Boud and Garrick, 2001) for example, has carried out significant research on expert knowledge and the processes that support PK sharing in the workplace, as well as the role of social constraints and the characteristics and limitations of the community of practice approach to support PK sharing. Expert knowledge can be gained from everyday experiences; domain-specific knowledge is necessary for the development of expertise; learning is a social

process; knowledge is embedded in practice (Tennant, 2001, p. 170). Workplace learning, according to Billett (2001), is supported by full participation in workplace activities, workers' awareness of the results of their activities, direct guidance from experts and indirect guidance provided by others and the environment. Among those components, the informal ones seem to be important. Informal or 'non-formal learning' (Eraut, 2000) involves implicit learning (there is no awareness and no intention to learn), reactive on-the-spot learning (near-spontaneous and unplanned learning but the learner is aware) and deliberate learning (there is intention to learn).

Similarly, the knowledge management literature (Zahra and George, 2002; Zollo and Winter 2002; Szulanski, 2000), has also explored the process of knowledge 'transfer', yet it has focussed in 
more explicit forms of knowledge, overlooking PK. Articulation, acquisition, communication, internalisation, application, absorption and dissemination are the most frequently used variables by this literature. Focussing on practical activities, Dougherty (2004), proposed that PK knowledge is generated through the enactment of three collective processes: interweaving designing and using; participating in the whole flow of designing and using; and reflecting in action. Complementing those ideas, the literature has also pointed out the key role of socialisation processes in knowledge sharing. Socialisation, in this study, is viewed as both formal and informal interaction between people that focuses on work issues (e.g. how operational tasks are deployed, current working conditions), organisational context, as well as on knowledge about the group (customs, norms, routines, jargon) and its members (who is good at what? and, how do I fit in?) that surround the intersubjective relations permeating the interpretation of task performance and outcomes (Moreland, Argote and Krishnan, 1996; Nicolini et al., 2003). Nonaka and Takeuchi (1995) noted that it is only through working together and developing informal social relationships that experiences can be shared. This paper, however, departs from Nonaka and Takeuchi’s (1995) contention that socialisation 'converts' tacit knowledge into explicit knowledge. While the above concepts constitute an advance on the understanding of the process of sharing $\mathrm{PK}$, there seems to be no consistency of findings (Tsai-Lung, 2007).

The community of practice approach (Lave and Wenger, 1991) emphasises that PK sharing is supported by the development of common values, shared identities and common knowledge. This approach argues that peripheral members (novices) become experts after the community accepts them. However, it cannot be assumed that community-of-practice members are willing to give away valuable personal knowledge. The literature (Contu and Willmott, 2003; Roberts, 2006; Huzzard, 2004) noted that the role of power issues shaping meaning and trust is usually overlooked, including the group leaders' preferences to negotiate particular meanings to the detriment of others. This means that PK sharing is a continuous negotiation process, which in turn is permeated by political and power issues (Billett, 2004; Huzzard, 2004; Nicolini et al., 2003).

This suggests that a significant portion of the literature has overlooked the crucial role of power (Gordon and Grant, 2004; Clegg and Ray, 2003). Since knowledge and power are intrinsically connected (Fillion and Rudolph, 1999; Prichard, Hull, Chumer and Willmott, 2000), it is not possible to discuss expert knowledge, learning or PK without relating them to issues concerning power. This literature seems to be taking a functionalist approach, since it has attempted to develop models in order to support PK sharing. In turn, this also implies that this literature has 
adopted a unitarist perspective (Burrell and Morgan, 1979), in which bias towards a consensual view of the world (Swan and Scarbrough, 2001) was developed by assuming that high trust and rational actions address organisational differences. Conversely, a small portion of the literature (Billett, 1996; Nicolini et al., 2003), considering the subjective, contextual historical and language aspects of the process of sharing PK, has included the power dimension in their analysis.

Thus, it is notable to observe that different literatures have in common the fact that most of the empirical research has been deployed in collaborative and participative workplace environments. Rather than focussing on how expert knowledge is learned assuming collaborative work environments, this research recognises that PK sharing is a learning process and focuses on the expert-novice socio-political relationships in order to understand how PK is shared in hostile work environments. Having as background the ideas presented in the previous sections, the process of sharing PK in a bio-pharmaceutical industry is presented after the methodology section.

\section{METHODOLOGICAL ASPECTS}

The process of PK sharing was examined at a bio-pharmaceutical industry that produces vaccines for veterinary use. Located in the countryside, the organisation is 30 years old and has 248 employees, comprising $26 \%$ office staff and $74 \%$ shopfloor staff. The plant was labour intensive as the level of process automation was low. The study took place in 2004 and lasted eight months. At the time of the empirical research, the firm was experiencing a process of transition of generations. On the one hand, there were experienced personnel (with more than 25 years in-house) close to retirement; on the other hand, there were fresh graduates hired less than a year earlier. The latter group needed to acquire the abilities of the experienced workers. The study focussed on the vaccine production process that typically involves formulation, filtration, bottling and packaging. The process is complex, since many raw materials need to be mixed at different stages and undergo multiple physic-chemical transformations. The focus of the present study was in the formulation stage. In this phase, PK was crucial, since standard work procedures do not detail 'how to' perform tasks. Formulation involves the selection of raw materials, the mixing of raw materials in order to produce the required (organic) cultures, the evaluation of organic cultures, homogenisation, cell count and the diffusion of micro-organisms in cellular suspension. This is a lengthy process, depending on the type of vaccine, with a lead-time of up to four months. PK in routine environments, therefore, can be more complex than it first appears. While there is a basic routine (process) to formulate products, because of the emergent nature of the process, small variations (for 
example, the quality of the raw material, the timing to carry out specific actions, the nature of previous products elaborated in the equipment to be used and room temperature) could lead to changes in the physic-chemical characteristics of the product, thereby determining the quality of the final product.

This study is interpretive (Burrell and Morgan, 1979) and qualitative (Bryman and Bell, 2003; Marshall and Rossman, 1998), since it requires an in-depth understanding of the social processes surrounding PK sharing and the situated tacit nature of PK in hostile industrial settings. Case study methodology (Yin, 1984) was used since it allows an in-depth comprehension of the specific macro and micro contextual conditions surrounding the PK sharing process, such as local production culture, employees' motivation, as well as the strengths and limitations of the production system. Specifically, this is an instrumental case study (Stake, 2005) because it aims at developing new insights about PK sharing in hostile environments. Case study methodology is also appropriate for the research goals because it both supports theory building (Eisenhardt, 1989) and adheres to the explorative character of the research (Voss, Tsikriktsis and Frohlich, 2002).

The research team was composed of two persons: the author, who designed the study and coded and analysed data, and a higher-degree student who, at the time of the research was working as a Quality Engineer at the bio-pharmaceutical company. She performed mainly data collection activities as participant observer. A range of data collection methods was used.

Because of the temporal, task-oriented and procedural nature of PK, participant observation was suitable for the qualitative and interpretive nature of the study. The participant observer had the unique opportunity to directly witness the whole production process, having constant access to the main personnel involved, and could understand simultaneously the strengths as well as the inherent social and technical pressures and limitations of the production process. Since the data collection process was carried out by an insider, well-known problems associated with direct observation, such as validity and reliability, were minimised (Adler and Adler, 1998). Despite formally having a Quality Control role, the research team-member acted as a non-participant peripheral observer since her responsibilities were not related to 'how to' develop bio-chemical activities in the production of vaccines. Rather, her day-to-day activities focussed more on the definition of production plans than in actual quality control activities. Participant observation was crucial to gain understanding of the nature of PK because the physical and situated nature of PK means that only through directly observing ongoing actions is it possible to gain partial understanding of the socio-political issues surrounding the realisation of PK. 
As participant observation by itself is insufficient to provide enough satisfactory explanations regarding the PK realisation (Adler and Adler, 1998), complementary interviews (Fontana and Frey, 1998) were carried out. Because of the situated nature of PK, interviews were both semi-structured and unstructured, formal and informal, and taken individually and in groups. Interviews spanned the whole data collection time (8 months). In the earlier stages, interviewees were separated into two groups - experts and inexperienced personnel, whereas in the latter stages, experts and inexperienced workers were interviewed together. By separating the two groups, it was possible to observe not only the different explanations given for specific actions but also enabled a better understanding of the different views that each group had regarding practice and, in particular, the 'non-technical' reason for some actions being taken and why others were not taken. Informal interviews were conducted in the field, while formal interviews occurred in offices. Individual informal interviews ranged from 3 to 15 minutes, asking usually on-the-spot questions related to specific actions. Formal individual interviews lasted 30 minutes on average and group interviews between 45 minutes and one hour. A total of 18 formal interviews and 29 informal interviews were performed during the span of the project. It must be noted that the combination of participant observation with interviews generated not only pluralistic explanations and data redundancy, but also supported triangulation (Silverman, 2005; Yin, 1981).

Company documentation and data available on company databases helped to better understand the complexities involved in practical tasks. Technical aspects of the production process, such as production schedules, staff allocation, raw material, equipment specifications, standard outputs and the actual protocols of the formulation area, were valuable sources of data.

The sample comprised ten staff members, namely the area supervisor, the plant manager and eight production staff members. Production staff included four experienced and four inexperienced individuals, who were distributed into two crews, each of which contained two experienced and two inexperienced staff members. This sample was opportunistic and theoretical. The fact that experienced individuals were resistant to share their PK with inexperienced ones matched research goals.

One of the challenges of case studies is how to avoid retrospective sense-making and bias during the interpretation of interview data (Einsenhart and Graebner, 2007; Stake, 2005). In order to minimise these issues, the study focussed, in the formulation stage. Additionally, two crews working on the same product - at different timeslots - were observed and interviewed during the life of the research. This strategy provided pluralistic explanations by different individuals 
regarding observed practices, behaviours, outcomes and processes, reducing the likelihood of misinterpretation and increasing the validity of the study.

The data collection and analysis evolved in three stages. First, because of the situated and diverse nature of practical tasks, direct observation data had necessarily to be complemented with interviews. Therefore, still during the process of data collection, and after a period of observation, data was reviewed in order to check for missing or unclear aspects of specific practical tasks. At this stage, data was coded and grouped having as reference the concepts of PK and PK sharing developed in the theoretical section. Yin (1981) noted that this is a well known strategy to analyse case study evidence. Since in the majority of cases data obtained from observations was insufficient, additional interviews were carried out. This was an ongoing process that happened on the spot (during the development of workers' day-to-day activities) and in special meetings. The participant observation method used enabled the research team to develop an interactive data collection and data analysis process. In the second stage, direct observation data was coupled with individual and group interview data regarding specific batches. In the third stage, in order to address potential bias by the participant observer, emerging themes were categorised independently by the two members of the research team and possible causal relationships were established. Approximately once a month, the research team jointly presented partial findings to participants from both crews to check for accuracy of description of events and to clarify practice diversity as well as interpretation disagreements. This process enabled the researcher to reduce natural cognitive limitations in dealing with data and developing inferences (Sadler, 2002).

\section{SHARING PRACTICAL KNOWLEDGE: ANALYSING THE EMPIRICAL EVIDENCE}

In order to facilitate the PK sharing in the vaccine formulation area, the firm applied two wellknown mechanisms to share knowledge: observation and learning-by-doing. Nevertheless, they were not helpful because of the hostile environment reigning in the organisation. Empirical findings can be categorised in two groups. On the one hand, some of the features of PK pointed out by the literature (Smith, 1988; Wenger, 1998; Brown and Duguid, 1991; Fruim, 1997; Orlikowski, 2002; Nicolini et al., 2003) are consistent with the empirical findings: (a) PK is complex since there are multiple dimensions - cognitive, sensorial and physical among others; (b) these dimensions have strong tacit components since in many cases it is not possible to articulate either 'how' or 'why'; (c) PK is situational; that is, only during the action will the executing person be aware of the specific local conditions of operation (specific nature/availability of raw materials, equipment etc.). Even in 
repetitive industries, such as in the case of bio-pharmaceuticals, specific conditions of operation are not necessarily the same since small variations in raw materials, equipment and team composition can affect the final result to a significant extent.

On the other hand, this empirical study has unravelled additional characteristics of the process of sharing PK. First, learning-by-observing has limitations in promoting PK sharing in hostile environments. While the literature (Gourlay, 2004; Styhre et al., 2006) has suggested that observing is an effective alternative to promote PK sharing, the empirical evidence does not conform with these findings. When inexperienced personnel were instructed to "observe all [activities of a team of experienced personnel] in detail”, they became "completely lost”, knowing "neither what to do nor where to look" [inexperienced worker 1]. They did not know what part of the process to pay attention to, since they had little (practical) knowledge on the current process. Additionally, they were not able to give attention to all activities as many of them occurred simultaneously. One of the inexperienced workers pointed out that he knew neither what activity was the most important in the process, nor did he have any idea of the sequence in which to mix raw materials. Polanyi (1958) labelled this behaviour as the relationship between 'part and whole'. In this situation, it is not possible to pay attention to the task and to the equipment simultaneously. When the focus of attention is directed to the equipment, the idea of the 'whole' is lost, and this then has the mental effect of disorganisation. Because of this complexity, the use of learning-by-observing does not seem to be enough to learn: "I think that I was able to understand what they [the experienced workers] have done, but to tell you that I know how to do it, I don't think so" [inexperienced worker 3].

It must be noted that it was difficult for the inexperienced to understand how a series of almost simultaneous activities was performed, not only because of the situational nature of tasks but also because they had no additional help from the experienced individuals. This means that, while the 'part and whole' cognitive issues significantly explain the shortcoming of the learning-byobserving idea, in order to be effective, additional explanations by experts are necessary, and this implies the existence of political willingness. The latter must not be taken for granted. This, however, is what happened at the bio-pharmaceutical firm. The factory manager, for example, assumed that “...by following all day [inexperienced workers] to experienced workers, they [the inexperienced ones] will end learning the job” [factory manager]. This means that the manager, in the initial stages of the research, understood PK as something 'physical' and as such, just observing 
would be sufficient to learn it. The empirical evidence, however, clearly showed that PK has both a practical and an intellectual dimension, constituted by tacit and personal knowledge. This was evident in the local knowledge applied by experienced workers during the mixing of the active component with the colorant. They knew a specific 'trick' to prevent the product from changing colour, which involved touching the product with one's hand in order to feel its viscosity:

in that product the active component need to be mixed in a special way and there is a 'right' time to mix it. The right time depends on the colour of the mix inside the tank. Did you see how he did it? Then, it is in that way ... [experienced worker 1].

This finding, therefore, highlights the intellectual (tacit and personal) and practical nature of PK and, in turn, it also implies the need of political willingness on the part of the experts to give away valuable PK. Conversely, it is also possible to infer that the intellectual and practical nature of PK helps to cover the unwillingness of experienced workers to disclose their PK. All this means that there is a political dimension that needs to be considered when applying a learning-by-observing approach since it will determine success or failure.

Second, because there is a wide range of alternative solutions for performing a specific task, sharing PK lends itself to political uses. Experienced workers needed not only to adapt the way they performed the task (e.g. sequence, timing) but also to know various ways of using equipment and tools in order to cope with unexpected limitations of the operation. For example, a pump failed during the transfer of a product and, because the inexperienced workers did not know what to do, experienced workers had to intervene, improvising a bypass in order to transfer raw materials. They knew not only how to build a bypass with available idle equipment, but also the likely consequences for the subsequent stages of the production process. This process is complex because it involves the actual physical transfer of materials while maintaining the physic-chemical conditions of the product in its unaltered state:

because of the problem with the pump, the process was performed in a different way than the previous day ... as a result I feel lost. There were a lot of new things; they [the experienced workers] made some tricks to connect the hose and turn on some controls in 
order to maintain the temperature stable. I do not know how to explain... [inexperienced worker 4].

It should be noted that the need to improvise a different way to perform the job provided experienced workers an important opportunity to show the inexperienced their knowledge-base power position. They knew not only the formal process to develop the practical task, but also alternative ways to perform it, as well as the different ways to use the equipment. This finding converges with Fuhrer's (1993) insight that a set of simultaneous activities needs to be targeted during the PK sharing process. The empirical evidence has extended this idea by noting that, for each activity, different alternative ‘solutions’ are possible. This point also extends Styhre et al.’s (2006) suggestion that PK sharing is intimately related to the use of artefacts. Data suggested that not only is the sharing of PK performed through the use of artefacts, but also that it is necessary to know the different 'applications' that are feasible with the available equipment.

Because of the wide spectrum of contingencies possible in PK, a wide range of alternative solutions do exist but are hidden. Depending on the different ways tasks are performed as well as on the different ways artefacts and ancillary equipment can be used, few alternative solutions will be open and a large number of solutions will be closed. This means that it is not difficult for the experts to not disclose knowledge about how practical activities are performed since the majority of alternative solutions are 'naturally' hidden. That is, experts do not need to do anything to not disclose crucial situated knowledge about PK. Thus, the situated nature of PK with its embedded 'hidden' alternative solutions not only constrains the process of sharing PK, but also facilitates the political use of access to a key resource such as particular knowledge (Pfeffer, 1981) and expertise (Pettigrew, 1973). In other words, the empirical data has pointed out that the situational nature of PK lends itself to be used in political terms.

Third, socialisation is important in order to facilitate the sharing of PK, but it is not enough. Political issues surrounding PK sharing are more important than socialisation processes. After three months of daily observation of the experienced workers' activities, inexperienced workers were able to produce a batch of output without many problems. This can be attributed not only to the continual follow-up of experienced workers' tasks, but also to the socialisation process that was naturally developed over time. Both groups started to socialise during lunchtime and breaks. Through socialisation, experienced workers tacitly understood that, in the short term, they could not be replaced by inexperienced workers. This situation converges with Lave and Wenger’s (1991) 
community of practice idea in terms that inexperienced workers only gained access to insider tacit knowledge after they were accepted by the experienced workers. Nevertheless, inexperienced workers were only accepted after experienced workers understood that the inexperienced would not be a threat to their jobs.

The above shows the crucial role of political aspects that surround the evolution of a community of practice. Although socialisation supports the sharing of PK, it does not guarantee it, as political issues seem to be stronger and might block PK sharing. Because the decision to collaborate or not to collaborate is a personal political choice, trust, local context and the perception of potential gains or losses are important elements of the decision making process (March, Schultz, and Zhou, 2000). The empirical evidence showed that socialisation processes are subordinate to political processes. This finding augments the conventional view that socialisation processes support PK sharing (Wenger, 1998). Here it is argued that socialisation is an important element of PK sharing, but its presence can be overcome by political forces. Therefore, an examination of the political environment is necessary in order not to take for granted collaborative attitudes among participants. This point must not be taken lightly since the knowledge and learning literatures usually overlook the political dimension that surrounds any social activity (Contu and Willmott, 2003; Huzzard, 2004).

Fourth, the use of standard work processes to share PK is limited in complex tasks. Standard work processes are set up to avoid process variation. For example, parameters of temperature, time and product mixing are set in order to produce consistent products every time. However, it was observed that in many cases standard work processes could not guarantee consistency in the characteristics of the final product:

in the formulae of fabrication is written the time to add the raw material into the tank. However I know that if I don't wait up to see the mix start to change its appearance because of the effect of inactivation of the virus, I am sure that the product will precipitate [i.e. it will fail] [experienced worker 2].

This finding differs from the well-established idea that organisational routines support learning and the transfer of knowledge (Becker, 2004). The empirical evidence suggests, on the one hand, that there are exceptions, and echoes Feldman (2000), in that organisational routines development implies in re-invention and interpretation. On the other hand, this finding also converges with the 
literature (Nicolini et al., 2003; Orlikowski, 2002) regarding the impossibility to codify the tacit components of PK. Additionally, because the tacit components of PK are situated, personal and subjective, sharing PK requires personal mechanisms to help an inexperienced individual to learn. This reiterates the previous point of the need for trust and willingness among experienced and inexperienced individuals, features not present in hostile environments. The above further highlights the role of political aspects that shape the PK sharing process.

\section{CONCLUSIONS}

This study aimed at analysing and evaluating an instance of the process of sharing PK in a hostile work environment. Based on a case study developed at a bio-pharmaceutical industry and focussing specifically on the manufacturing of vaccines, this study has extended previous learning and knowledge theories by pointing out additional features of the PK sharing process. First, learning-byobserving has limitations in promoting PK sharing in hostile environments, since there is a need for experts to explain the logic of the set of practical tasks performed simultaneously. This implies the existence of political will to give away that knowledge, a key issue that must not be taken for granted. Second, because there is a wide range of alternative solutions for performing a specific task, sharing PK lends itself to political uses. Third, socialisation is important in order to facilitate the sharing of PK, but it is not enough. Political issues surrounding PK sharing are more important than socialisation processes. Fourth, the use of standard work processes to share PK is limited in complex tasks.

The examination of the process of sharing PK in hostile environments, therefore, allowed the examination of constraining aspects that otherwise would go unnoticed in consensual work environments. The research findings highlighted that in hostile environments the political dimension seems to be more important than cognitive and organisational aspects of the PK sharing process. Trust, collaboration and willingness of experienced individuals to share their PK assets, therefore, must not be taken for granted, either in consensual or in hostile work environments. The rise of the political dimension in the PK sharing process is related to the insight that the main features of PK - situated, tacit, personal, emergent, temporary and with a wide range of alternative solutions - generate high levels of uncertainty. In high uncertainty environments, as Buchanan and Badham (1999) put it “... difficult choices are typically resolved by political means ... because rational arguments and empirical evidence may be lacking given the uncertainties surrounding such decision” (p. 12). The above means that the political dimension must be incorporated into the 
research agenda to examine the process of sharing PK, something that the knowledge and learning literatures have so far overlooked. Considering this, research findings need to be further qualified.

Firstly, insights from the case study hint at the heterogeneous nature of PK. Having in mind the matrix presented in Figure 1, it is possible to suggest that PK can take different forms depending on the extent to which, on the one hand, it is more or less tacit or explicit, and, on the other hand, more or less intellectual and action-based. Broadly speaking, PK can be either tacit-oriented or explicit-oriented. In the case of explicit-oriented PK, the role of political issues certainly will be lower than in the case of tacit-oriented PK. In the latter, because of the situated nature of tasks and multiple possible alternative solutions, uncertainty is high and therefore political issues acquire a prominent role.

Secondly, workplace environments are not, in reality, either collaborative or hostile. Conversely, there is a wide range of workplace environments that might vary from almost general collaboration to total hostility, with significant grey areas in which collaboration in some areas coexists with hostility in other areas. This means that the application of our research findings is not straightforward and must be carefully contextualised in order to be useful for practitioners. Thus, considering the varied nature of workplace environments, it is possible to suggest that in collaborative-oriented environments, operational, cognitive and social aspects are likely to be more important than political issues since political agreement among individuals has, implicitly or explicitly, been reached. Conversely, in hostile-oriented environments, socio-political issues need to be addressed before there is any attempt to apply advice provided by the knowledge and learning management literature.

Finally, as in any case study, there are limitations to how far the empirical findings can be generalised. Although it is not possible to generalise from a single case study (Yin, 1981), the new insights proposed certainly contribute to build more encompassing theories of PK sharing. Furthermore, it must be noted that the empirical evidence focussed on the analysis of an instance of PK sharing in the manufacturing sector. Additional studies focussing on different dimensions of PK and in different industries are needed in order to test our insights. For example, studies targeting tacit-oriented PK or explicit-oriented PK might increase our understanding of the role of political issues in the PK sharing process. 


\section{REFERENCES}

Adler, P. and Adler, P. (1998), “Observational techniques”, in Denzin, N. and Lincoln, Y.S. (Eds.), Collecting and Interpreting Qualitative Materials, Sage, Thousand Oaks, CA, 79-109.

Ackroyd, S. and Thompson, P. (1999), Organizational Misbehaviour, Sage, London.

Argyris, C. and Schön, D. (1974), Theory in Practice, Jossey-Bass, San Francisco.

Baumard, P. (1999), Tacit Knowledge in Organizations, Sage, London.

Becker, M.C. (2004), “Organizational routines: a review of the literature”, Industrial and Corporate Change, Vol. 13 No. 4, pp. 643-677.

Berragan, L. (1998), "Nursing practice draws upon several different ways of knowing”, Journal of Clinical Nursing, Vol. 7, pp. 209-217.

Billett, S. (1994), "Situated learning - a workplace experience”, Australian Journal of Adult and Community Education, Vol. 34 No. 2, pp. 112-130.

Billett, S. (1996), "Situated learning: bridging sociocultural and cognitive theorising”, Learning and Instruction, Vol. 6, pp. 263-280.

Billett, S. (2001), “Guided learning at work”, in Boud, D. and Garrick, J. (Eds.), Understanding Learning at Work, Routledge, London, pp. 151-164.

Billett, S. (2004), “Workplace participatory practices”, The Journal of Workplace Learning, Vol. 16 No. 6, pp. 312-324.

Blackler, F. (1995), "Knowledge, knowledge work and organizations: an overview and interpretation”, Organization Science, Vol. 16, No. 6, pp. 1021-46.

Blackler, F. and McDonald, S. (2000), "Power, mastery and organizational learning”, Journal of Management Studies, Vol. 37 No. 6, pp. 833-851.

Boud, D. and Garrick, J. (2001), "Understandings of workplace learning”, in Boud D. and Garrick, J. (Eds.), Understanding Learning at Work, Routledge, London, pp. 1-11.

Bourdieu, P. (1990), The Logic of Practice, Polity Press, Cambridge.

Brauner, E., Becker, A. and Jordan, S. (2005), "Organizational learning: the interplay of routinization and crisis in practices", in Gherardi, S. and Nicolini, D. (Eds.), The Passion for Learning and Knowledge, Vol. I., University of Trento, Trento, pp. 133-154.

Brown, J.S., Collins, A. and Duguid P. (1989), "Situated learning and the culture of learning”, Educational Researcher, Vol. 18 No. 1, pp. 32-34.

Brown, J.S. and Duguid P. (1991), "Organizational learning and communities-of-practice”, Organization Science, Vol. 2 No. 1, pp. 40-57. 
Brown, J.S. and Duguid P. (2001), “Knowledge and organizations: A social-practice perspective”, Organization Science, Vol. 12 No. 2, pp. 191-213.

Bryman, A. and Bell, E. (2003), Business Research Methods, Oxford University Press, New York.

Buchanan, D. and Badham, R. (1999), Power, Politics and Organizational Change, Sage, London.

Burawoy, M. (1979), Manufacturing consent, University of Chicago Press, Chicago.

Burrell, G. and Morgan, G. (1979), Sociological Paradigms and Organizational Analysis, Heinemann, London.

Carper, B. (1978), "Fundamental patterns of knowing in nursing”, Advances in Nursing Science, Vol. 1 No. 1, pp. 13-23.

Clegg, S. and Ray, T. (2003), "Power, rules of the game and the limits of knowledge management: lessons from Japan and Anglo-Saxon alarms”, Prometheus, Vol. 21 No. 1, pp. 23-40.

Contu, A. and Willmott, H. (2003), "Re-embedding situatedness: the importance of power relations in learning theory”, Organization Science, Vol. 14 No. 3, pp. 283-296.

Cook, S. and Brown, J. (1999), "Bridging epistemologies: the generative dance between organizational knowledge and organizational knowing”, Organization Science, Vol. 10 No. 4, pp. 381-400.

Delbridge, R. (2000) Life on the line in contemporary manufacturing, Oxford University Press, Oxford.

Dosi, G., Nelson, R.R. and Winter, S. (2002), The Nature and Dynamics of Organizational Capabilities, Oxford University Press, Oxford.

Dougherty, D. (2004), “Organizing practices in services: capturing practice-based knowledge for innovation”, Strategic Organization, Vol. 2 No. 1, pp. 35-64.

Eisenhardt, K. (1989), “Building theories from case study research”, Academy of Management Review, Vol. 14 No. 4, pp. 532-550.

Einsenhart, K. and Graebner, M. (2007), “Theory building from Cases: Opportunities and Challenges”, Academy of Management Journal, Vol. 50 No. 1, pp. 25-34.

Eraut, M. (2000), “Non-formal learning and tacit knowledge in professional work”, British Journal of Psychology, Vol. 70, pp. 113-136.

Feldman, M. (2000), “Organizational routines as a source of continuous change”, Organization Science, Vol. 11, pp. 611-629.

Fillion, N. and Rudolph, H. (1999), “Power, control and organisational learning”, Wissenschftszentrum Berlin für Sozialforschung, Discussion paper FSI 99-104, Berlin. 
Fontana, A. and Frey, J. (1998), “Interviewing: the art of science”, in Denzin, N. and Lincoln, Y. (Eds.), Collecting and Interpreting Qualitative Materials, Sage, Thousand Oaks, pp. 47-78.

Fruim, M. (1997), Knowledge Works - Managing Intellectual Capital at Toshiba, Oxford University Press, New York.

Fuhrer, U. (1993), "Behavior setting analysis of situated learning: the case of newcomers”, in Chaiklin, S. and Lave, J.(Eds), Understanding Practice - Perspectives on Activity and Context, Cambridge University Press, Cambridge, pp. 179-211.

Garrick, J. (2001), “Dominant discourses of learning at work”, in Boud, D. and Garrick, J. (Eds.), Understanding Learning at Work, Routledge, London, pp. 216- 231

Gherardi, S. (2000), “Practice-based theorizing on knowing and learning in organizations”, Organization, Vol. 7, pp. 211-223.

Gordon, R. and Grant, D. (2004), “Knowledge management or management of knowledge? Why people interested in knowledge management need to consider Foucault and the construct of power”, Tamara - Journal of Critical Postmodern Organization Science, Vol. 3 No. 2, pp. 2738.

Gourlay, S. (2004), “Knowing as semiosis: steps towards a reconceptualization of tacit knowledge”, in Tsoukas, H. and Mylonopoulos, N. (Eds.), Organizations as Knowledge Systems, Palgrave, Basingstoke, pp. 86-101.

Handley, K., Sturdy, A., Fincham, R. and Clark, T. (2006), "Within and beyond communities of practice: making sense of learning through participation, identity and practice”, Journal of Management Studies, Vol. 43 No. 3, pp. 641-633.

Huzzard, T. (2004), “Communities of domination? Reconceptualising organisational learning and power”, The Journal of Workplace Learning, Vol. 16 No. 6, pp. 350-361.

Ickes, W. \& R. Gonzalez (1996), “Social’ cognition and social cognition”, In Nye, J.L. and Brower, A.M. (Eds.), What's Social about Social Cognition?, Sage, London, pp. 285-308.

Lave, J. (1993), “The practice of learning”, in Chaiklin, S. and Lave, J. (Eds.), Understanding Practice - Perspectives on Activity and Context, Cambridge University Press, Cambridge, pp. 3-32.

Lave, J. and Wenger, E. (1991), Situated Learning - Legitimate Peripheral Participation. Cambridge University Press, Cambridge.

Leftwich, A. (1983) Redefining politics, Methuen, London.

March, J., Schultz, M. and Zhou, X. (2000), The Dynamics of Rules, Stanford University Press, 
Stanford.

Marshall, C. and Rossman, G. (1998), Designing Qualitative Research, Sage, New York.

Moch, S. (1990), "Personal knowing: evolving research and practice”, Scholarly Inquiry for Nursing Practice, Vol. 4 No. 2, pp. 155-165.

Moreland, R. L., Argote, L. and Krishnan, R (1996), "Socially shared cognition at workTransactive memory and group performance”, in Nye, J.L. and Brower, A.M (Eds.), What's Social about Social Cognition?, Sage, London, pp. 57-84.

Nicolini, D., Gherardi, S. and Yanow, D, (2003), "Introduction: toward a practice-based view of knowing and learning in organizations”, in Nicolini, D., Gherardi, S. and Yanow, D. (Eds.), Knowing in Organizations, M.E. Sharpe, Armonk, New York, pp. 3-31.

Nonaka, I. and Takeuchi, H. (1995), The Knowledge Creating Company, Oxford University Press, Oxford.

Nyiri, J.C. (1988), "Tradition and practical knowledge”, in Nyiri, J.C. and Smith, B. (Eds.), Practical Knowledge: Outlines of a Theory of Traditions and Skills, Croom Helm, Kent, pp. 17-52.

O’Connor, E. (2005), “Embodied knowledge - the experience of meaning and the struggle towards proficiency in glassblowing”, Ethnography, Vol. 6 No. 2, pp. 183-204.

Orlikowski, W. (2002), "Knowing in practice: enacting a collective capability in distributed organizing”, Organization Science, Vol. 13 No. 3, pp. 249-273.

Orr, J. (1996), Talking about Machines: An Ethnography of a Modern Job, Cornell University Press, Ithaca, NY.

Pettigrew, A.M. (1973), The Politics of Organizational Decision Making, Tavistok, London.

Pfeffer, J. (1981), Power in Organizations, Pitman, Mass.

Polanyi, M. (1958), Personal Knowledge. Towards a Post-Critical Philosophy, Routledge and Kegan Paul, London.

Prichard, C., Hull, R., Chumer, M. and Willmott, H. (2000), "Introduction: Situating discussions about 'knowledge'”, in Prichard, C., Hull, R., Chumer, M. and Willmott, H. (Eds.), Managing Knowledge - Critical Investigations of Work and Learning, St. Martin Press, New York, pp. $\mathrm{xV}-\mathrm{xxx}$.

Raelin, J. (2005), “The role of facilitation in praxis”, Organizational Dynamics, Vol. 35 No. 1, pp. 83-95.

Reckwitz, A. (2002), “Towards a theory of social practices: a development in culturalist 
theorizing”, European Journal of Social Theory, Vol. 5 No.2, pp. 243-263.

Revans, R.W. (1966), The Theory of Practice in Management, Macdonald, London.

Roberts, J. (2006), “Limits to communities of practice”, Journal of Management Studies, Vol. 43 No. 3, pp. 623-639.

Rolfe, G. (1997), "Beyond expertise: theory, practice and the reflective practitioner”, Journal of Clinical Nursing, Vol. 6, pp. 93-97.

Ryle, G. (1962), The Concept of Mind, Barnes \& Noble, New York.

Sadler, R. (2002), “Intuitive data processing as potential source of bias in naturalistic evaluations”, in Huberman, A. and Miles, M. (Eds.), The Qualitative Researcher’s Companion, Sage, Thousand Oaks, CA, pp. 123-135.

Schatzki, T., Knorr-Cetina, K. and Von Savigny, E. (2001), The Practice Turn in Contemporary Theory, Routledge, London.

Schon, D. (1983) The Reflective Practitioner, Basic Books, New York.

Scribner, S. (1986), “Thinking in action: some characteristics of practical thought”, in Sternberg, R. and Wagner, R. (Eds.), Practical intelligence: Nature and Origins of Competence, Cambridge University Press, Cambridge

Smith, B. (1988), “Knowing how vs. knowing that”, in Nyiri, J.C. and Smith, B. (Eds.), Practical Knowledge: Outlines of a Theory of Traditions and Skills, Croom Helm, Kent, pp. 1-16.

Sole, D. and Edmondson, A. (2002), "Situated knowledge and learning in dispersed teams”, British Journal of Management, Vol. 13, pp. 7-34.

Stake, R. (2005), “Qualitative Case Studies”, in Denzin, N. and Lincoln, Y. (2005) The Sage Handbook of Qualitative Research, Sage, London, Third Edition, pp. 443-466.

Storey, J. (1983), Managerial prerogative and the question of control, Routledge \& Kegan Paul, London.

Styhre, A., Josephson, P. and Knauseder I. (2006), “Organization learning in non-writing communities”, Management Learning, Vol. 37 No. 1, pp. 83-100.

Swan, J. and Scarbrough, H. (2001), "Knowledge management: concepts and controversies”, Journal of Management Studies, Vol. 38 No. 7, pp. 913-922.

Szulanski, G. (2000), “The process of knowledge transfer: a diachronic analysis of stickiness”, Organizational Behaviour and Human Decision Processes, Vol. 82 No. 1, pp. 9-27.

Tennant, M. (2001), “Is learning transferable?”, in Boud, D. and Garrick, J. (Eds.), Understanding Learning at Work, Routledge, London, pp. 165-179. 
Thompson, M. and Walsham, G. (2004), "Placing knowledge management in context”, Journal of Management Studies, Vol. 41 No. 5, pp. 725-747.

Tsai-Lung, L. (2007), “Knowledge transfer: past research and future directions”, The Business Review, Cambridge, Vol. 7, No. 1, pp. 273- 281.

Tsoukas, H. (2000), “Knowledge as action, organization as theory: reflections on organizational knowledge”, Emergence, Vol. 2 No. 4, pp. 104-112.

Tsoukas, H. (2005), “Do we really understand tacit knowledge?”, in Easterby-Smith, M. and Lyles, M. (Eds.), The Blackwell Handbook of Organizational Learning and Knowledge Management, Blackwell Publishing, Cornwall, pp. 410-427.

Tsoukas, H. (2006), “Talking about machines - tenth anniversary”, Organization Studies, Vol. 27 No. 12, pp. 1741-1742.

Voss, C., Tsikriktsis, N. and Frohlich, M. (2002), “Case research in operations management”, International Journal of Operations \& Production Management, Vol. 22 No. 2, pp. 195-219.

Watson, T. (1995), Sociology of work and industry, Routledge, London, Third edition.

Weick, K. (1995), Sensemaking in Organizations, Sage, Thousand Oaks, CA.

Wenger, E. (1998), Communities of Practice, Cambridge University Press, Cambridge.

Yin, R. (1984), Case Study Research, Sage, Thousand Oaks, CA.

Zahra, S. and George, G. (2002), “Absorptive capacity: a review, reconceptualization and extension”, Academy of Management Review, Vol. 20 No. 2, pp. 185-203.

Zollo, M. and Winter, S. (2002), “Deliberate learning and the evolution of dynamic capabilities”, Organization Science, Vol. 13 No. 3, pp. 339-352. 


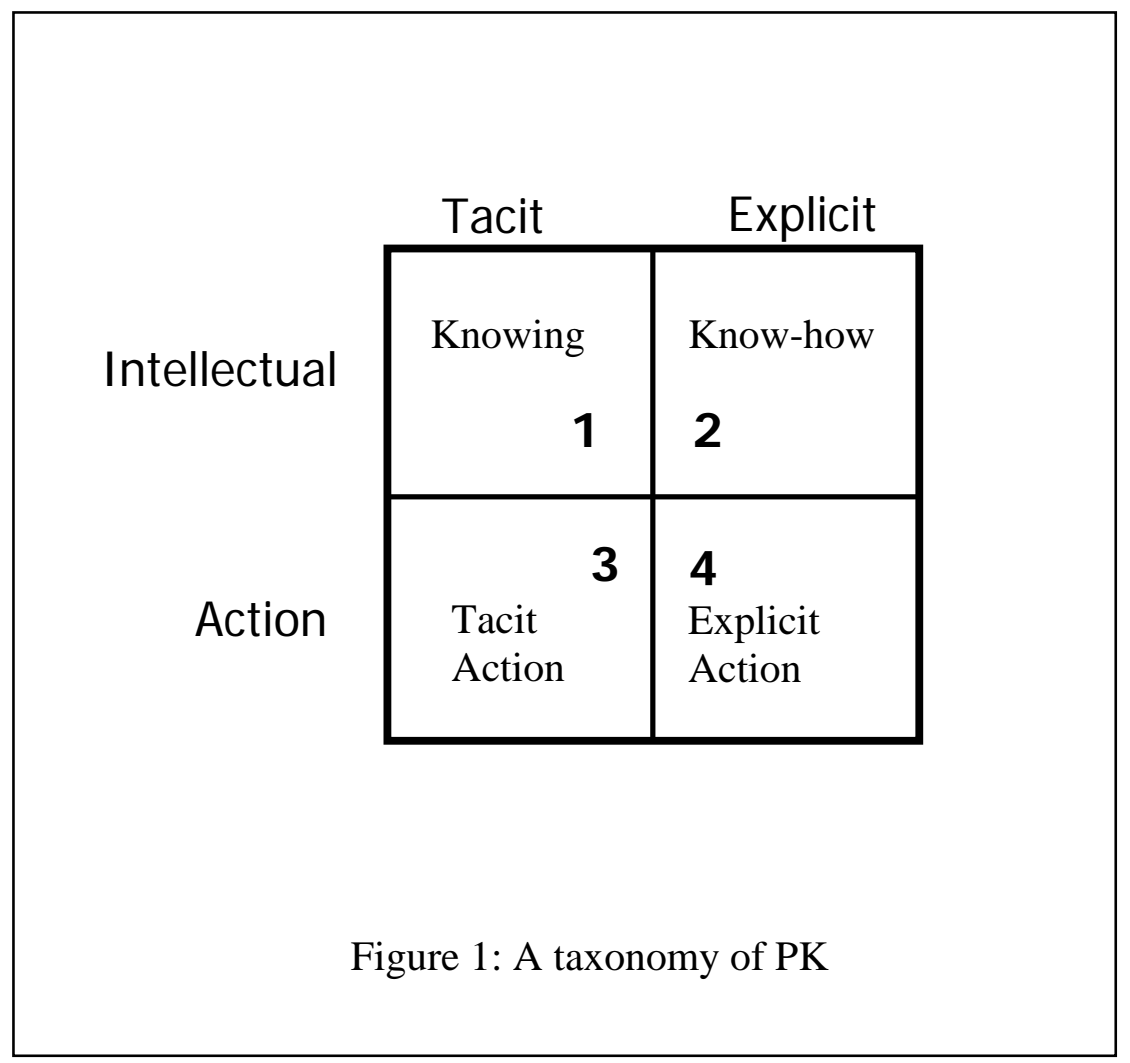

Source: Designed for this study 